\title{
The Industrial Need of Technically Trained Men
}

\author{
Engineering as a Life Work-Electrical Engineering
}

By W. H. Abbott

For a young man who is about to choose a profession, it is often a most.preplexing question what that profession should be. Happy is he who has a most decided predilection which is actually based on the peculiar bent of his mind. 'The inherited callings, for instance, being a doctor because one's father is a doctor, is a most dangerous thing, since it so frequently happens that the candidate has never had a chance to even consider anything else.

Every mind seems to have additional powers in certain directions. Under a competitive system of existence, it is more than wise to follow this line of least resistance, no matter how desirable it may be to cultivate the qualities which we lack in order to make full rounded men. I would suggest that the qualities lacking be selected as hobbies and cultivated during one's leisure time.

Another point on which the young man is very likely to go wrong is that he thinks that he should not take a college course, but should begin at the bottom and work up on the practical side, since the practical side is so highly prized in the business world. This seems logical and is if he will remember that he must learn everything covered in the college course, even though he does begin in the shop. Practice is a wonderful thing as an aid to theory, and if one starts early enough it does not matter very much which comes first, but both must be had. The college course, in connection with the college laboratory, is probably the easiest solution of a most difficult problem.

Further than this, even in electrical engineering, there are positions to which an engineer may aspire which do not require an engineering training, yet an engineer may fill them to advantage as compared with a man with a business training only. Such positions always carry with them salaries and a consideration superior to that of engineering alone, and are obtained not by engineering ability but by those other qualities which distinguish men, and which qualities are greatly enhanced by a college training. The qualities themselves are, however, probably inborn and cannot be originated by any form of training.

The first question that the candidate must decide is, has he the quality of mind which would justify him in choosing some form of engineering? The quality of mind which probably embraces all forms of engineering is that of an infinite curiosity directed more particularly to happenings in the world we call matter. For instance, an infinite curiosity pertaining only to men should make a sociologist, to mind alone a psychologist, to all things equally a philosopher. To curiosity as to matter, must also be united the desire to be a builder or operator; this last being the distinetion between the quality of mind of the scientist and the engineer.

Given the curiosity and the actual desire for manipulation, one can safely conclude that he is fitted for some form of engineering. The matter of choice then becomes paramount. Again it reduces itself to a question of quality of mind. The various branches of engineering quality of mind. The various branches of engineering dealt with and the kind of motion to which they are subjected. For instance, in bridge and structural work, the masses are usually large and the condition of lack of motion is the cardinal principle; in hydraulics, the masses of water are frequently acres in extent and the motion usually slow. The same applies to mining. In railroad work, the masses are smaller and the motion faster. In mork, the masses are smaller and the motion faster. In mechanical work, the elements are usually small and the
motion fast. In metallurgical work, the particles in action are very small and the motion becomes that of the molecules of the matter. In pure electrical work, the masses are the smallest and the motion exceedingly fast, being that of the smallest divisions of matter. In other words, we progress from matter at rest to matter in its highest stage of motion. The choice should therefore depend on which of these divisions of size and motion depend on which of these divisions of size and motion
most interests us. Which we can most readily visualize and think about without undue strain. At the very bottom, they are probably all equally difficult, but not for all minds.

No doubt the psychologists will soon have some tests worked up that will enable us to distinguish much more clearly as to what are our mental qualifications. Many mistakes would be avoided if some decisive tests could be applied.

At this point, however, it is important to point out that since the divisions between the branches are graduations of mass or motion or both, they necessarily overlap. This is particularly true of electrical and mechanical engineering. All truly electrical phenomena show themselves or are produced by mechanical means, and usually through more or less complicated mechanical tools. Hence these two divisions go so elosely together that many college faculties for a long time refused to separate them. Even though the separation has now been made, it seems that the practice of many students in combining the two courses. is advisable even if it takes somewhat onger.

The similarity of mechanical and electrical engineering is strikingly shown by the main subdivisions of each.

Electrical Engineering $\left\{\begin{array}{l}\text { Light. } \\ \text { Power. } \\ \text { Transportation. } \\ \text { Transmission. }\end{array}\right.$
Mechanical Engineering $\left\{\begin{array}{l}\text { Power. } \\ \text { Transportation. } \\ \text { Transmission. } \\ \text { Manufacturing. }\end{array}\right.$

Both are doing practically the same work, but are doing it in a different way. The electrical method in nearly every case is to substitute for a series of mechanical forms some simple electrical form usually operated at a higher velocity. This substitution of electrical detail for mechanical details is proceeding very rapidly in all manufacturing industries. To make such substitution requires, however, as wide a mechanical knowledge as an electrical. It will not be at all surprising to find a strong subdivision springing up in the future, the specialists in which will call themselves electro-mechanical engineers, in the same way that we already have electrometallurgists. The quality of mind for each of the above leans strongly to the electrical. This is seen very elearly among skilled workmen in construction operations. The best mechanical helpers are uncertain of themselves as soon as some piece of electrical apparatus is injected into a machine. Many of them seemingly cannot think alon the combined lines and are willing to give up on little difficulties on which they would have spent hours striving for a solution if along mechanical lines alone.

The very latest developments indicate that the close connection between electrical and mechanical engineering is rapidly extending to all branches of engineering In other words, that we are to have electro-metallurgists, hydro-electric engineers, electro-mining engineers and electric railway engineers. All of them must get their initial training along electrical lines and then specializ among the subdivisions; the subdivision thereafter becoming their principal subject. In other words, the province of electricity in these subdivisions seems to be either in the elimination of mechanical parts or in an increase in the output. Hence the engineer must be most thoroughly acqnainted with the fundamental possibilities of electricity.

If then a young man is attracted by electric phenomena that is, can readily visualize the unseen, and in addition is strongly attracted by some other department of engineering, he can readily combine the two and find a field sufficiently wide for all his ambitions.

All actual practice of engineering divides itself into operation and design.

Operation includes all erection work and must be the field of the majority of engineers. In electrical work, due to the large factories establishing student courses, this fact has been somewhat overlooked. The factory for the manufacture of electrical apparatus is the hom of the designing engineer. Hence, if from the financial standpoint it is necessary for a young engineer to advance rapidly and he is not a born designer, he had better not spend too many years in the factory.

The operating engineer should be active physically and have a more general education than the designing ongineer. He will come in contact with the public at ever turn, and the public will not appreciate his detailed knowledge of electricity or mechanies. A man who knows things in general will appeal to it as an able man - and success in many places is determined by what the public thinks.

The operating engineer must also have a knowledg of business or merchandising. All successful operatio is measured by the two sides of a ledger account. An operating engineer must face that ledger and know something of how the accountant manipulates it. Reputations are made and marred behind the bookkeeper's desk as well as around the work benches. An operating man who can check accounts or make up his own statemen of what it is costing him can weather more storms than one who is in the hands of his "friends."

In many departments of operation, the social side of the manager counts for much. In electric light operatio it frequently makes the difference between a successful it frequently makes the difference between a successful
and an unsuccessful man. The ability to dance well will make stronger friends and more of them than artistic draftsmanship, although that is desirable. In other words, the full rounded man is the one looked for as manager of all public service corporations, and the number of these is legion.

The designing engineer must be a specialist. $\mathrm{He}$ is the student of the engineering fraternity. His theoretical training should be most thorough. He must have that rare combination, the mathematical mind combined with originating genius. Most of all, he must realize the importance of details, and the detailed history of his proportance

The number of positions open for designing engineers is small. The road to design is up through the drafting room and out through the complaint department. All present -day practice is toward standardization, which much reduces the field of the designer, and that not infrequently to the damage of the apparatus turned out. Standardization has been carried to its greatest extreme in this country. The largest field still open is in the design of systems or combinations of units, as in laying out power houses, transmission lines, or factories. This. however, more frequently falls to the operating engineer than it really should, due to the operating man being in closer contact with the owners or financiers of such enterprises.

\section{Rare Gases}

Thermal springs all give off rare gases. It is a wellestablished fact that neon, argon, krypton, xenon and helium are all found in the mixture of gases emitted from such sources, as also that if the first four are present in the same proportion as in air, the fifth, helium, is always found in larger proportion, sometimes much larger. Thus, at Maizieres the crude gas contains nearly 6 per cent of helium.

Mouren and Lepape, who have made extensive studies in this line, have found still larger percentages of helium elsewhere. At Santenay, three springs gave off a gas in which the amount of helium varied from 8.4 to 10.6 per cent.

These figures suggest that there are actual deposits of helium in the neighborhood of springs which emit gases.

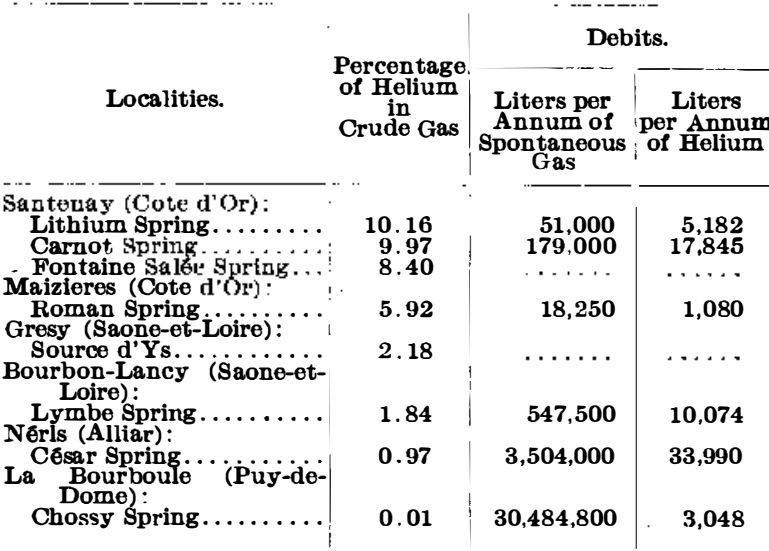

Helium being one of the products of the disintegration of radio-active substances, it is believed that this helium of thermal springs is either very young, disengaged as produced, or else entirely fossil, i. e., liberated a very long time subsequent to its accumulation in the minerals. But the question is, which?

The Carnot spring yields 17,845 liters per annum, but it would require 91 tons of radium, or $500,000,000$ tons of pitchblend or thorianite to produce this volume, if we accept the first hypothesis. For the second, the annual disaggregation of 2 tons of thorianite, or 167 tons of pitchblend, or 300,000 tons of granite would suffice. Hence the second hypothesis appears more reasonable.

It will be noted that the first five places in the table lie in a strip of territory oriented southwest to northeast. Obviously considerable deposits of helium must be located within this strip.-Bibliotheque Univers.

Map of the World to a Scale of One Millionth M. Charles Lallemand, Director of the Service and
Organization of the General Leveling of France, has given some information concerning the last conference of the international map of a millionth scale. At the first conference, which was held at London in 1909, only seventeen countries were represented. At the present time thirty-one states have joined the convention. M. Lallemand also announced that the Prince of Monaco was taking upon himself the expense of several oceanic pages.-Chemical News. 